\title{
Relationship between the intensive care unit beds and mortality by COVID-19 in Brazil
}

\author{
Carlos Dornels Freire de Souza1* (1), Gibson Barros de Almeida Santana' (1),

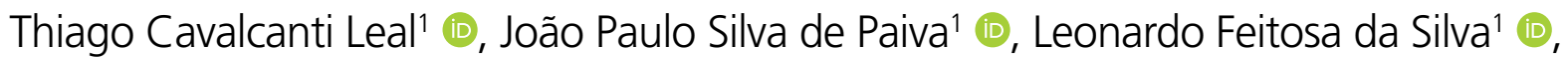 \\ Lucas Gomes Santos ${ }^{1}\left(\mathbb{D}\right.$, Victor Santana Santos ${ }^{2}\left[10\right.$, Rodrigo Feliciano do Carmo ${ }^{3}$
}

\section{INTRODUCTION}

Coronavirus disease 2019 (COVID-19) is a highly infectious disease, which may progress rapidly to pneumonia or acute respiratory distress syndrome (ARDS), requiring mechanical ventilatory support in intensive care units $(\mathrm{ICU})^{1}$. As the disease spreads rapidly and the fatality rate is high among patients with severe conditions, the availability of ICU beds has been considered as one of the strategies to face the disease and avoid deaths ${ }^{1-3}$.

Globally, COVID-19 has affected more than 3 million people and caused more than 225,000 deaths in the first quarter of $2020^{4}$. The number of deaths has been high even in countries with well-structured health systems or having high number of ICU beds for severe cases ${ }^{4}$. As the disease spreads to low- and middle-income countries, we better understand the differential effects of COVID-19 according to socioeconomic positions.

Due to the community transmission of COVID-19, the number of cases and deaths increased exponentially and in April 4, 2020 more than 100,000 cases and 7,000 deaths had already been detected across Brazil. Brazil has 32,757 adult ICU beds, of which $45 \%$ of them allocated to the Unified Health System (Sistema Único de Saúde [SUS], in Portuguese), which are concentrated in states with better socioeconomic conditions ${ }^{5}$.

Thus, this study described the distribution of ICU beds and its relationship with the mortality rate due to COVID-19 in Brazil until the pandemic stage.

\section{METHODS}

We conducted an ecological study referring to all COVID-19 deaths from March 17 to April 24, 2020 and their relationship with ICU bed availability indicators in Brazil.

Data were obtained from three different sources. Data on deaths were obtained from the Brazilian Ministry of Health on April 24, 2020. Information on the number of beds for each state was obtained from the National Registry of Health Establishments (CNES) and population data from the Brazilian Institute of Geography and Statistics (IBGE). From the data, we calculated for each state the mortality rate per 1 million population, the general rate of ICU beds for adults per 100,000 population, and the rate of ICU beds for adults per 100,000 population allocated in the public and private health systems. It is important to note that the case fatality rate was not analyzed since the low availability of the tests results in overestimated rates.

Moran's bivariate spatial correlation model and multivariate regression (ordinary least square) were used to verify the spatial relationship between the availability of ICU beds, the number of deaths, and the mortality rate of the states. In the regression analysis of the mortality rate, adjustment was made for the total number of deaths. A 95\% confidence interval and a $5 \%$ significance level were adopted. This study did not require the approval of the Research Ethics Committee since we used public domain data.

\footnotetext{
'Universidade Federal de Alagoas, Department of Medicine - Arapiraca (AL), Brazil.

${ }^{2}$ Universidade Federal de Alagoas, Center for Epidemiology and Public Health - Arapiraca (AL), Brazil.

3Universidade Federal do Vale de São Francisco, Department of Pharmacy - Petrolina (PE), Brazil.

*Corresponding author: carlos.freire@arapiraca.ufal.br

Conflicts of interest: the authors declare there is no conflicts of interest. Funding: none.

Received on December 03, 2020. Accepted on December 13, 2020.
} 


\section{RESULTS}

Between Mach 17 and April 24, 2020, Brazil accounted for 3,670 deaths by COVID-19. The highest numbers of deaths were recorded in São Paulo ( $\mathrm{n}=1.512)$, Rio de Janeiro $(\mathrm{n}=570)$, and Pernambuco $(\mathrm{n}=352)$ states, respectively. Amazonas state has the highest mortality rate (60.14 deaths/ 1 million; 255 deaths), followed by Pernambuco (36.47/1 million; 352 deaths), Rio de Janeiro (33.64/1 million; 570 deaths), São Paulo (32.82/1 million; 1512 deaths), and Ceará (30.94/1 million; 284 deaths).

Overall, the Federal District had the highest rate of adult ICU beds per 100,000 population $(107.6 / 100,000)$ and Roraima state had the lowest rate $(4.1 / 100,000)$. Considering only SUS adult ICU beds, Minas Gerais (12.5/100,000) and Sáo Paulo (12.2/100,000) had the highest rates, while Amapá state had the lowest rate $(1.5 / 100,000)$. In the private health network, the highest rates were observed in the
Federal District (347.8/100,000 users) and Mato Grosso (66.3/100,000 users).

A significant correlation was observed between the number of deaths and the rate of ICU beds for adults per 100,000 population (Moran's $\mathrm{I}=0.157275 ; \mathrm{p}=0.02$ ) and the rate of ICU beds for adults per 100,000 population allocated in the private health system (Moran's $\mathrm{I}=0.157916 ; \mathrm{p}=0.04$ ). No significance was observed in the multivariate regression model (Figure 1).

An inverse correlation between the COVID-19 mortality rate and the rate of adult ICU beds in public health services was demonstrated in both bivariate (Moran's $\mathrm{I}=-0.136756$; $\mathrm{p}=0.03$ ) and multivariate (coefficient $=-0.4073 ; \mathrm{p}=0.035)$ analysis. There was no correlation between COVID-19 mortality and the rate of adult ICU beds available in private health services (Figure 2). a) Bivariate spatial correlation

Adult ICU beds per 100,000

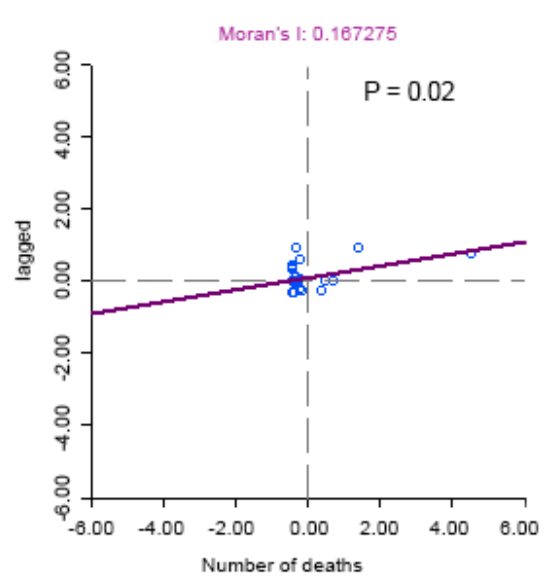

b) Multivariate regression

Model 1 - Number of deaths

\begin{tabular}{|c|c|c|c|c|}
\hline Variable & Coefficient & Std. Error & t-Statistic & P-value \\
\hline Constant & 129.552 & 76.972 & 1.683 & 0.10 \\
\hline No. total of ICU adult beds per 100,000 & 0.42157 & 3.2038 & 0.1315 & 0.89 \\
\hline R- squared: 0.0006 & \multicolumn{2}{|c|}{ Schwarz: 391.055} & \multicolumn{2}{|c|}{ Log likelihood: -192.232 } \\
\hline \multicolumn{5}{|l|}{ Model 2 - Number of deaths } \\
\hline Variable & Coefficient & Std. Error & t-Statistic & P-value \\
\hline $\begin{array}{l}\text { Constant } \\
\text { No. of SUS-ICU adult beds per } 100,000 \\
\text { No. of privates-ICU adult beds per } 100,000\end{array}$ & $\begin{array}{l}-79.2926 \\
31.2372 \\
-0.4723\end{array}$ & $\begin{array}{l}159.091 \\
18.740 \\
0.9616\end{array}$ & $\begin{array}{l}-0.4795 \\
1.6668 \\
-0.49121\end{array}$ & $\begin{array}{l}0.63 \\
0.10 \\
0.62\end{array}$ \\
\hline R- squared: 0.1114 & \multicolumn{2}{|c|}{ Schwarz: 391.18} & \multicolumn{2}{|c|}{ Log likelihood: -190.64} \\
\hline
\end{tabular}

Adult ICU beds - privates per 100,000

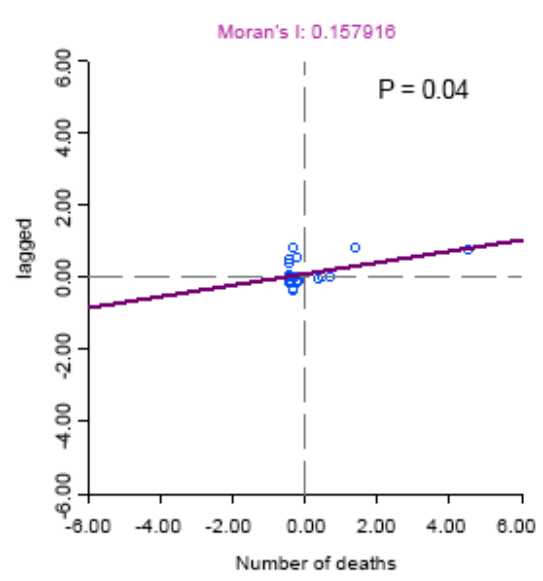

Adult ICU beds - SUS per 100,000

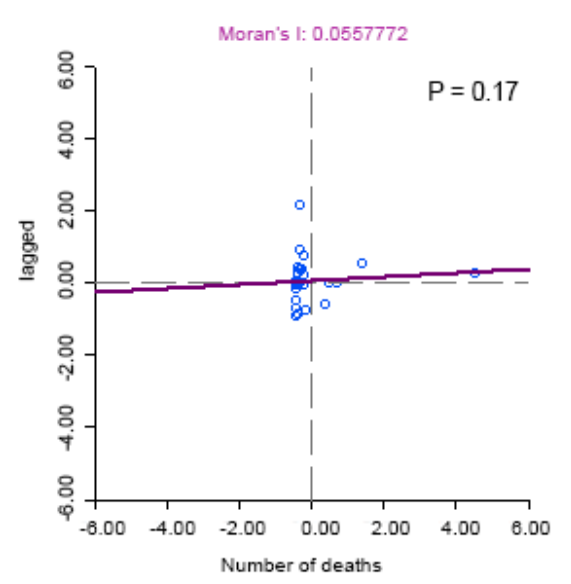

Figure 1. Bivariate spatial correlation and multivariate regression between the number of deaths by COVID-19 and the availability of intensive care units beds in Brazil, 2020. COVID-19, coronavirus disease 2019; intensive care units; SUS, Sistema Único de Saúde. 


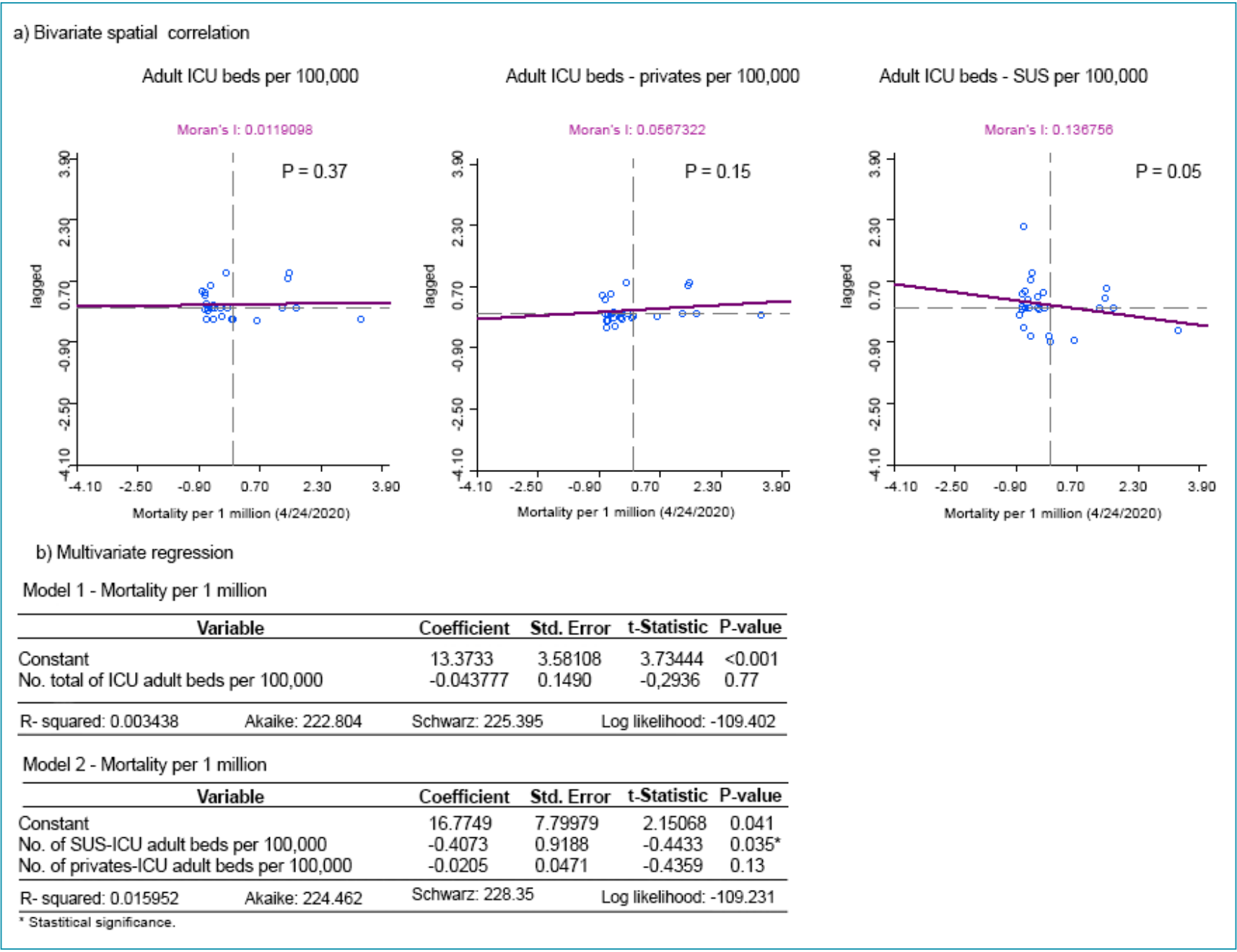

Figure 2. Bivariate spatial correlation and multivariate regression between the mortality rate by COVID-19 and the availability of intensive care unit beds in Brazil, 2020. COVID-19, coronavirus disease 2019; intensive care unit; SUS, Sistema Único de Saúde.

\section{DISCUSSION}

This study showed that the distribution of adult ICU beds in Brazil occurs heterogeneously among the Brazilian states. In addition, there was an inverse relationship between the mortality rate due to COVID-19 and the adult ICU rate in public services.

Brazil has considerable social, economic, and health resource disparities among the states. Despite the wide network of health services, which includes 5,922 hospitals and 563 public health laboratories ${ }^{6,7}$, there are inequities in the distribution of these resources. States located in the North and Northeast regions historically had the highest inequalities regarding the provision of health services.

The North region presents one of the worst social and health conditions, including low human development in $46 \%$ of the municipalities, low number of physicians per 100,000 population, and a pragmatic social vulnerability ${ }^{8-10}$. In addition, this study found that North region has the lowest number of ICU beds $(n=1,331)$ and the lowest proportion of SUS beds per population ( 0.9 bed per 100,000 population). In Amazonas state-one of the states most affected by COVID-19 pandemic-the ratio of physicians working in municipalities distant from the capital Manus city is 0.2 per 100,000 inhabitants and Amazonas has only $271 \mathrm{ICU}$ beds as reference to approximately $4.2 \mathrm{mil}-$ lion people, resulting in a rate of $6.5 / 100,000$ population. In addition, 182 of 271 adult ICU beds are available for SUS patients $(5.0 / 100,000)^{5,7}$.

Similar to the North region, the Northeast region has poor social and health conditions and the COVID-19 crisis has exacerbated the health problems ${ }^{10}$. For example, the states of Pernambuco, Ceará, and Piauí are already presenting a overcrowding of adult ICU beds. On April 30, Pernambuco 
state-the state with the second largest number of adult ICU beds in the Northeast region $(\mathrm{n}=1,382)$-already had $99 \%$ of the ICU beds in the public service occupied ${ }^{11}$.

In Brazil, an estimated $80 \%$ of population depends exclusively on health services provided by SUS ${ }^{8}$. Thus, the significant increase in the number of COVID-19 cases, with a consequent increase in the number of critically ill people requiring intensive care, may overburden the public health system. This situation can be aggravated by the fact that $75 \%$ of health regions have insufficient numbers of ICUs to guarantee the care of the population before COVID-195. Regardless of the COVID-19 pandemic, the expectation for ICU beds will certainly increase, as already observed in other countries ${ }^{12}$, and this situation would cause more pressure on the public health system. Seriously, the lack of ICU beds would result in increased mortality from both COVID-19 and other diseases requiring hospitalization.

ICU care generates higher costs to the system, and in the case of COVID-19 the costs may be higher because of the long hospital stay of people in treatment for the disease. However, in recent years, the largest health service provider in Brazil has suffered from a lack of public investments; austerity policies, restrictions on public spending, underfunding, and the lack of political interest are obstacles to strengthen the SUS. The Constitutional Amendment No. 95, of December 15, 2016, is an example of this process of reducing the public health system. This amendment prevents the increase in health care costs for 20 years, starting in 2017, and represents the most serious threat to the principles that sustain SUS (Universality, Integrality, and Equity $)^{13}$. In the face of the COVID-19 pandemic, the Brazilian response could be more effective if SUS had received the necessary investments.

Nevertheless, due to the epidemiological scenario installed in Brazil, some measures have been taken by the state authorities. As a strategy for coping with COVID-19, many Brazilian states, because of the low rate of ICU beds, have provisionally constructed field hospitals to exclusively treat COVID-19 patients, spawned a monthly national expense of 10.5 million $^{14}$. However, it is important to note that these field hospitals are temporary structures, and after the pandemic, SUS will continue with the same structural problems as earlier. Therefore, it is of fundamental importance that investments in the public health system are continuous and guarantee the necessary support to its users even after the pandemic.

This study has some limitations. Underreporting may occur since our analyses were performed from secondary data, and they depend on the capacity of health and surveillance services. Another limitation is the lack of data on ICU beds for children. However, we believe that this does not compromise our findings due to the low mortality rate in this age group. In addition, the nonavailability of hospitalization rate represents an important limitation. Thus, the causal relationship cannot be established solely from ecological studies.

\section{CONCLUSIONS}

This study showed the importance of ICU beds as a determinant of mortality. It is urgent to expand the care network for patients with COVID-19 and to strengthen other measures that can reduce the transmission curve, relieving the health system. Monitoring of such measures is necessary to provide more information about how the COVID-19 pandemic behaves in a country with disparities in the allocation of health resources like Brazil.

\section{AUTHORS" CONTRIBUTION}

CDFS: Conceptualization, Data Curation, Formal Analysis, Project Administration, Writing - Original Draft, Writing Review and Editing. GBAS: Conceptualization, Data Curation, Formal Analysis, Project Administration, Writing - Original Draft, Writing - Review and Editing. TCL: Conceptualization, Data Curation, Formal Analysis, Project Administration, Writing - Original Draft, Writing - Review and Editing. JPSP: Conceptualization, Data Curation, Formal Analysis, Project Administration, Writing - Original Draft, Writing Review and Editing. LFS: Conceptualization, Data Curation, Formal Analysis, Project Administration, Writing - Original Draft, Writing - Review and Editing. LGS Conceptualization, Data Curation, Formal Analysis, Project Administration, Writing - Original Draft, Writing - Review and Editing. VSS: Conceptualization, Data Curation, Formal Analysis, Project Administration, Writing - Original Draft, Writing - Review and Editing. RFC: Conceptualization, Data Curation, Formal Analysis, Project Administration, Writing - Original Draft, Writing - Review and Editing.

\section{REFERENCES}

1. Zhu N, Zhang D, Wang W, Li X, Yang B, Song J, et al. A novel coronavirus from patients with pneumonia in China, 2019.
N Eng J Med. 2020;382(8):727-33. https://doi.org/10.1056/ NEJMoa2001017 
2. Ye Z, Song B. Liver injury in COVID-19: diagnosis and associated factors. Liver Int. 2020;40(8):2040-1. https://doi.org/10.1111/ liv. 14501

3. Shi Y, Yu X, Zhao H, Wang H, Zhao R, Sheng J. Host susceptibility to severe COVID-19 and establishment of a host risk score: findings of 487 cases outside Wuhan. Crit Care. 2020;24(1):108. https://doi.org/10.1186/s13054-020-2833-7

4. Johns Hopkins University. Coronavirus Resource Center: COVID-19 dashboard by the Center for Systems Science and Engineering (CSSE) [Internet]. 2020 [cited on Apr 26, 2020]. Available from: https://coronavirus.jhu.edu/map.html

5. Rache B, Rocha R, Nunes L, Spinola P, Malik AM, Massuda A. Necessidades de infraestrutura do SUS em preparo a COVID-19: leitos de UTI, respiradores e ocupação hospitalar. Instituto de Estudos para Políticas de Saúde: Nota Técnica n 3 [Internet]. 2020 Março [cited on Apr 28, 2020]. Available from: https:// ieps.org.br/wp-content/uploads/2020/04/IEPS-NT3.pdf

6. Duarte E, Eble LJ, Garcia LP. 30 anos do Sistema Único de Saúde. Epidemiol Serv Saúde. 2018;27(1):e00100018. http:// doi.org/10.5123/s1679-49742018000100018

7. Brasil. Cadastro Nacional de Estabelecimentos de Saúde [Internet]. Brasília: Ministério da Saúde; 2020 [cited on Apr 24, 2020]. Available from: http://cnes.datasus.gov.br/

8. Paim JS. Sistema Único de Saúde (SUS) aos 30 anos. Ciênc Saúde Coletiva. 2018;23(6):1723-8. https://doi.org/10.1590/141381232018236.09172018
9. Rotta BP, Silva JM, Fu C, Goulardins JB, Pires-Neto RC, Tanaka C. Relação entre a disponibilidade de serviços de fisioterapia e custos de UTI. J Bras Pneumol. 2018;44(3):184-9. https:// doi.org/10.1590/S1806-37562017000000196

10. Garnelo L, Lima JG, Rocha ESC, Herkrath FJ. Acesso e cobertura da Atenção Primária à Saúde para populações rurais e urbanas na região norte do Brasil. Saúde Debate. 2018;42(1):81-99. https://doi.org/10.1590/0103-11042018S106

11. Falcão M. Taxa de ocupação das UTIs da rede pública em Pernambuco atinge 99\% [Internet]. Recife: Valor Econômico; 2020 [cited on Apr 30, 2020]. Available from: https://valor. globo.com/brasil/noticia/2020/04/20/taxa-de-ocupacao-dasutis-da-rede-publica-em-pernambuco-atinge-99percent.ghtml

12. Srinivasan SR. Editorial: Tele-ICU in the age of COVID-19: built for this challenge. J Nutr Health Aging. 2020;24(5):536-7. https://doi.org/10.1007/s12603-020-1376-6

13. Mendes A, Carnut L, Guerra LDS. Reflexões acerca do financiamento federal da Atenção Básica no Sistema Único de Saúde. Saúde Debate. 2018;42(spe1):224-43. https://doi. org/10.1590/0103-11042018S115

14. Brasil. Ministério da Saúde. 220 leitos de UTI custeados pelo Ministério da Saúde em cinco estados [Internet]. Brasília: Ministério da Saúde; 2020. [cited on Apr 24, 2020]. Available from: https://antigo.saude.gov.br/noticias/agencia-saude/46740220-leitos-de-uti-custeados-pelo-ministerio-da-saude-emcinco-estados 